\title{
Chaenomeles speciosa fruit endophytic fungi isolation and characterization of their antimicrobial activity and the secondary metabolites composition
}

Yurii V. Lykholat ${ }^{*}$, Nina O. Khromykh², Oleh O. Didur²®0, Oksana A. Drehval ${ }^{3}$, Tetyana V. Sklyar ${ }^{3}$ and Andrii O. Anishchenko ${ }^{4}$

\begin{abstract}
Background: Endophytes promote the survival of the host plants affected by unfavorable environment. To confirm the endophytes role in Chaenomeles speciosa pathogenic resistance, fungal isolates were derived from both fruit peel and pulp, and presumptively identified using macroscopic and microscopic techniques. Antifungal potential of the isolates was assayed by dual culture method and agar disc method against Alternaria alternata, Fusarium culmorum, and Fusarium oxysporum strains. Two most active fungal isolates were cultured in Czapek's liquid medium to obtain metabolites. The crude ethyl acetate extracts of metabolites were characterized for antibacterial activity against Basillus subtilis and Erwinia dissolvens, and for component composition by GC-MS technique.

Results: Nine fungal endophytic isolates were derived from the peel and pulp of C. speciosa fruits and tentatively attributed to Penicillium spp. (seven isolates), Aspergillus spp. (one isolate), Mucor spp. (one isolate). Two fungal isolates, one each of the fruit peel and pulp, were designated as Penicillium sp. I and Penicillium sp. II respectively, and selected for further research. Both isolates showed similar activity against A. alternata; however, Penicillium sp. I activity against F. culmorum and F. oxysporum exceeded the activity of Penicillium sp. II. Cultural medium ethyl acetate extracts of both endophytes exhibited higher antibacterial activity against Gram-positive B. subtilis, while mycelium extracts were more active against Gram-negative E. dissolvens. In general, Penicillium sp. I antibacterial activity was higher in cultural medium extracts, while activity of Penicillium sp. II dominated in mycelium extracts. GC-MS analysis of the fungal metabolites component composition revealed the identity of 27 and 17 compounds, respectively in the ethyl acetate extracts of Penicillium sp. I and Penicillium sp. II cultural medium. Basic compounds produced by the first isolate, were represented by 3-Furanacetic acid, 4-hexyl-2,5-dihydro-2,5-dioxo, Diisooctyl phthalate, 11-Hexadecyn-1-ol, and Propanedioic acid, dihydroxy. At the same time, Phthalic acid diisooctyl ester and other phthalates constituted the main part of the second isolate metabolites, followed by Hexadecanoic acid, Eicosyl isopropyl ether, and 4-Butoxy2-butanone at a lower content.
\end{abstract}

Conclusions: The findings showed that the antimicrobial potential of Chaenomeles fruits endophytic fungi is promising and deserves further investigation.

\footnotetext{
*Correspondence: lykholat2006@ukr.net

${ }^{1}$ Plant Physiology Department, Faculty of Biology and Medicine, Oles

Honchar Dnipro National University, Gagarin Av., 72, Dnipro 49010,

Ukraine

Full list of author information is available at the end of the article
} original author(s) and the source, provide a link to the Creative Commons licence, and indicate if changes were made. The images or other third party material in this article are included in the article's Creative Commons licence, unless indicated otherwise in a credit line to the material. If material is not included in the article's Creative Commons licence and your intended use is not permitted by statutory regulation or exceeds the permitted use, you will need to obtain permission directly from the copyright holder. To view a copy of this licence, visit http://creativecommons.org/licenses/by/4.0/. 
Keywords: Chaenomeles fruit, Endophytes, Metabolites, Antimicrobial activity

\section{Background}

Endophytic microorganisms colonize the inner intercellular space of plant asymptomatically, not harming the hosts, but optimizing their interaction with the environment using different mechanisms. This may be a direct effect of endophytic fungi on pathogen, which reducing plant leaves infestation [1], or the competition of endophytes with pathogens for substrates as well [2]. Coevolution with endophytes in natural ecosystems has enriched plants with numerous bioactive compounds [3], which have been used by mankind for centuries as plantinherent components. The discovery that anticarcinogenic agent taxol is a secondary metabolite of endophytic fungi, served as a powerful stimulus for the examination of other endophytes metabolic potential [4]. In the recent years, endophytic microorganisms have been isolated from plants of different taxa and ecological groups, as well as from different plant organs, including leaves, stems, and rhizosphere [5]. Despite the differences in the endophytes habitats, the compounds they produce are often useful and provide one or more therapeutic effects, including bactericidal [6], antifungal [7], cytotoxic [8], antimutagenic [9], and antitubecular [10]. It becomes obvious that the endophytes isolation and cultivation has opened up new possibilities for obtaining necessary biologically active compounds instead of traditional extraction from plants [11].

The plants of genus Chaenomeles Lindley (Rosaceae family, Magnoliopsida class) grow naturally in southeast Asia, and were the important resource in traditional medicine for their ability to improve human health [12], which is explained by the accumulation of polyphenols and triterpenes $[13,14]$. In the steppe zone of Ukraine, several Chaenomeles species have been successfully adapted and bear fruit [15], accumulating high level of the phenolic compounds [16] and showing greater resistance to pathogens common in the region as compared to other fruit plants [17]. Similarly, minimal fungal diseases susceptibility was indicated for Chaenomeles species in the other different areas [18, 19], which may be associated with the protective function of endophytes. However, there is little information about the endophytic community of Chaenomeles plants, except for the great diversity of C. speciosa mycorrhizal fungi [20]. In a previous study, we found a quite long shelf life of $C$. speciosa fruits after harvesting [15], which also may suggest the endophytes contribution to antipathogenic resistance. The aim of this work was to isolate the endophytic fungi from the C. speciosa fruits, discover antimicrobial potential of the isolates and identify metabolites produced by the endophytes.

\section{Methods}

\subsection{Plant material collection}

Fruits of the C. speciosa plants were taken from the Botanical Garden of Oles Honchar Dnipro National University $\left(48^{\circ} 26^{\prime} 7{ }^{\prime \prime} \mathrm{N}, 35^{\circ} 2^{\prime} 34^{\prime \prime}\right.$ E, Dnipro city, Ukraine). Here, plants of the genus Chaenomeles Lindl. have been introduced more than 25 years ago in the steppe climate with low precipitation ( $473 \mathrm{~mm}$ average, but $265 \mathrm{~mm}$ in dry years) and sharp temperature changes. Ripe fruits of C. speciosa were collected in the first half of September 2020 , packed in plastic containers and taken to the laboratory immediately. The samples were washed with warm water, and then sterilized by sequentially immersing in $70 \%$ ethanol for $30 \mathrm{~s}$ and $4 \%$ sodium hypochlorite solution for $30 \mathrm{~s}$, rinsed with sterile distilled water, and finally fired in a burner.

\subsection{Endophytes isolation and identification}

Portions of fruits peel and pulp (about $2.0 \mathrm{~g}$ each) were taken with a sterile scalpel and ground in a sterile mortar pestle with the addition of $10 \mathrm{ml}$ of sodium chloride solution (0.5\%). Aliquots $(1 \mathrm{~mL})$ of each suspension were inoculated on three different media, namely Potato Dextrose Agar (PDA), Meat Peptone Agar (MPA), and Gause's medium in sterilized Petri plates, followed by the plates were kept at $28.0 \pm 0.2{ }^{\circ} \mathrm{C}$ for 6 days. Then, the Petri plates were examined visually, and hyphae from distinct colonies were inoculated in the new Petri plates with PDA and incubated until colonies were formed. After incubation, pure cultures were transferred to PDA slants and stored at $4{ }^{\circ} \mathrm{C}$ until have been using for the further investigations. Macroscopic and microscopic techniques were the base for the identification of endophytic microorganisms. Macroscopic exploration of the endophytes morphology included revealing such features of colony as form, size, color, and hyphae. Micrography of the slides prepared from a fungal mycelium small portion and stained with methylene blue was carried out at $40 \times$ magnification using an Ulab XY-B2T LED microscope equipped with a trinocular attachment for connecting a digital camera-eyepiece.

\subsection{Antagonistic activity bioassay by dual culture method} Antagonistic ability of the fungal isolates was evaluated by using dual culture method [21] against phytopathogenic fungi Alternaria alternata (strain KMB-F-16 from 
the collection of Microbiology, Virology and Biotechnology Department of Oles Honchar DNU) and Fusarium culmorum (strain IMB-F-50716 provided by the Microbiology and Virology Institute named after Zabolotny, Kyiv, Ukraine). Mycelium discs (7 $\mathrm{mm}$ in diameter) of actively growing 6-day-old cultures of pathogens and isolated endophytes were placed in Petri plates with PDA medium at an equal distance from the periphery. Control plates were inoculated with pathogenic fungus only. Plates were incubated at $28 \pm 0.2{ }^{\circ} \mathrm{C}$ for nine days, and isolates antagonistic ability was measured as the percent inhibition (PI \%) based on the equation PI \% $=\left[\left(\mathrm{S}_{1}-\mathrm{S}_{2}\right) /\right.$ $\left.S_{1}\right] \times 100$, where, $S_{1}$ is the pathogen control colony area; and $S_{2}$ is the pathogen colony area in presence of endophytic isolate.

\subsection{Antagonistic activity bioassay by agar disc method} Modified agar disc method [22] was used to estimate the antifungal activity of isolated endophytes against both the above-mentioned pathogens and also Fusarium oxysporum (strain IMB-F-54201 from Microbiology and Virology Institute named after Zabolotny). Spores suspension of each pathogen in saline was inoculated into Petri plates with Czapek's medium and kept for $4 \mathrm{~h}$ at room temperature, after which agar disks (7 $\mathrm{mm}$ in diameter), cut from an actively growing culture of isolates, were placed on the Czapek's medium surface. Plates were incubated at $28 \pm 0.2{ }^{\circ} \mathrm{C}$ for five days, and antagonistic ability of isolates was expressed as the inhibition zone diameter $(\mathrm{mm})$. The isolates of endophytic fungi showed the highest inhibition ability in both antagonistic activity assays were selected for small scale fermentation.

\subsection{Cultivation and extraction of the fungal metabolites}

The endophytic fungi isolated from the fruits peel (Penicillium sp. I) and pulp (Penicillium sp. II) were cultivated in submerged conditions. For this, a small piece of PDA slants containing fungal mycelium was transferred to $500 \mathrm{~mL}$ Erlenmeyer flask, containing $200 \mathrm{~mL}$ of Czapek's liquid medium of sterilized $\mathrm{H}_{2} \mathrm{O}$, previously autoclaved at $121{ }^{\circ} \mathrm{C}$ for $40 \mathrm{~min}$. After inoculation, the medium was incubated for 6 days at $28 \pm 1{ }^{\circ} \mathrm{C}$ with constant shaking of $160 \mathrm{rpm}$. Then, mycelia biomass was separated from the aqueous medium by filtration through a Whatman No. 1 filter, and filtrates were extracted three times with an equal volume ethyl acetate (EtOAc), using a separating funnel. Combined ethyl acetate extracts evaporated at $40{ }^{\circ} \mathrm{C}$ using rotary evaporator (IKA ${ }^{\circledR} \mathrm{RV} 10$, Germany), and obtained solid fraction stored at $4{ }^{\circ} \mathrm{C}$ prior to analysis. The mycelium biomass ground with the addition of ethyl acetate, was kept in the dark for $24 \mathrm{~h}$, then filtered and evaporated to dryness. For bioassays and GC-MS analysis, the residues were dissolved in ethyl acetate and filtered through a syringe filter.

\subsection{Antibacterial activity assessment}

Antibacterial activity of crude ethyl acetate extracts of endophytic fungi was determined by the disc diffusion method [23]. Both endophytes cultural broth extracts and mycelium biomass extracts were screening for their antibacterial activity. Petri plates containing MPA medium were seeded with $109 \mathrm{cfu}$ (colony forming units) suspension of Gram-positive test bacteria Basillus subtilis (environmental sample, strain 168) and Gram-negative Erwinia dissolvens (environmental sample, strain 170) both from the culture collection of Microbiology, Virology and Biotechnology Department of Oles Honchar DNU. Sterile paper discs (6 $\mathrm{mm}$ diameter) were impregnated with $20 \mu \mathrm{l}$ of crude ethyl acetate extract and placed on the agar surface, followed by plates incubation at $37{ }^{\circ} \mathrm{C}$ for $24 \mathrm{~h}$. Ofloxacin (5.0 $\mu \mathrm{g}$ per disc) and ceftriaxone (30.0 $\mu \mathrm{g}$ per disc) were used as the positive control. Inhibition zones produced by the EtOAc extracts were measured and antibacterial activity was expressed as the diameter of the inhibition zone ( $\mathrm{mm}$ ).

\subsection{Gas chromatography-mass spectrometry (GC-MS) analysis of the fungal metabolites content}

Component composition of the crude ethyl acetate extracts was studied by the capillary gas chromatography connected to mass-spectrometry assay. GC-MS analysis of the extracts was performed using Shimadzu GCMS-QP 2020 El equipped with $\mathrm{Rxi}^{\circledR}{ }^{-} 5 \mathrm{~ms}$ column $(30 \mathrm{~m} \times 0.25 \mathrm{~mm}$, film thickness $0.25 \mu \mathrm{m})$ containing $5 \%$ diphenyl/95\% dimethyl polysiloxane as a fixed liquid phase. The column temperature was kept at $50{ }^{\circ} \mathrm{C}$ for $5 \mathrm{~min}$, and then programmed temperature gradient increased to $300{ }^{\circ} \mathrm{C}$ at a rate of $15^{\circ} \mathrm{C}$ per min and kept constant at $300{ }^{\circ} \mathrm{C}$ for $6.5 \mathrm{~min}$. The carrier gas helium passed at a flow rate $54 \mathrm{ml} / \mathrm{min}$. Injector temperature was $300{ }^{\circ} \mathrm{C}$; sample volume was $1 \mu \mathrm{l}$. Peak areas of the separated compounds were integrated automatically. Mass Spectrum Library 2014 for GC-MS (O2125401310) was used to identify the separated compounds by comparing the mass spectra obtained with mass spectra of known compounds stored in the library database. The content of ethyl acetate extract individual components was expressed as a peak area percentage of total amounts.

\subsection{Statistical analysis}

All bioassays were carry out in triplicate. The data obtained were calculated using Microsoft Excel XP 2007 and expressed as the Mean \pm Standard Deviation, and the differences between means were tested with Tukey's 
HSD. All differences were considered to be statistically significant at $P<0.05$.

\section{Results}

\subsection{Endophytes identification}

Total, peel and pulp of the C. speciosa fruits yielded nine fungal endophytic isolates. On the base of tentative macroscopic and microscopic identification, the endophytes have been attributed to Penicillium spp. (7 isolates, both from peel and pulp), Aspergillus spp. (one isolate from the fruit peel), and Mucor spp. (one isolate from the fruit peel). In this study, antimicrobial ability of the fungal isolates attributed to Penicillium spp. was tested, and two isolates which showed higher activity against more than one tested strains were designated as Penicillium sp. I (isolate from the fruit peel) and Penicillium sp. II (isolate from the fruit pulp). The colonies of both isolates had characteristic features of shape, color, and size. Microscopic observation of the stained mycelium slides confirmed the differences of selected Penicillium spp., in particular in the conidiophores morphology (including their length and width), and the conidia size (Fig. 1).

\subsection{Antagonistic activity evaluation}

Results of dual culture bioassay on PDA medium showed the high antagonistic activity of Penicillium sp. I against both tested pathogenic fungi $A$. alternata and $F$.
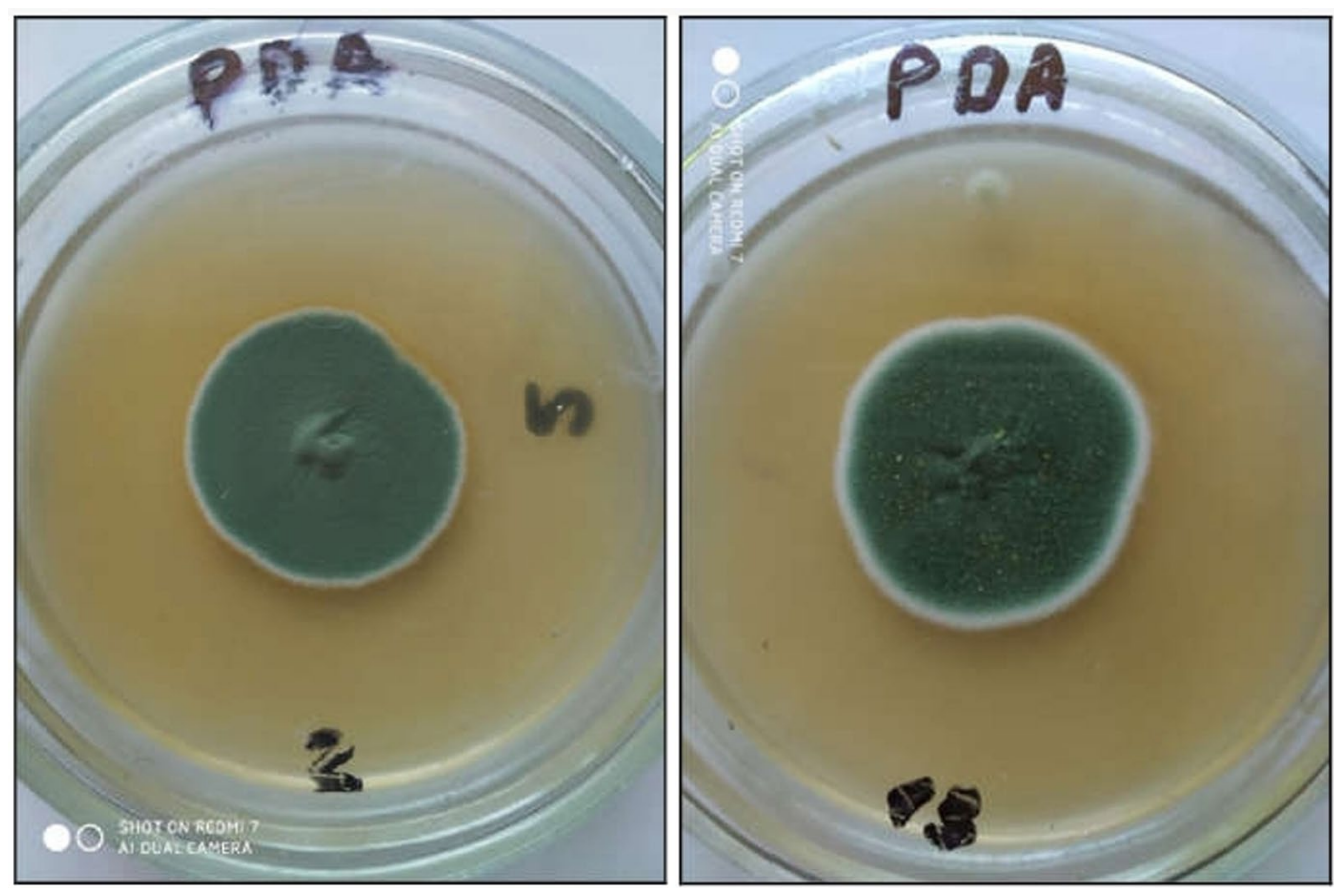

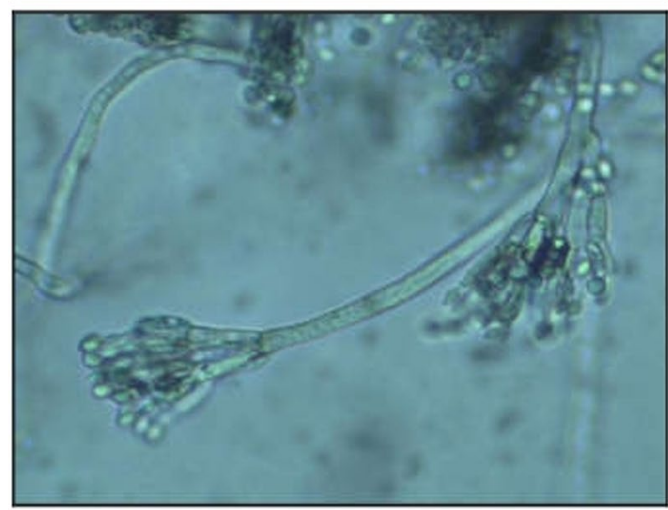

A

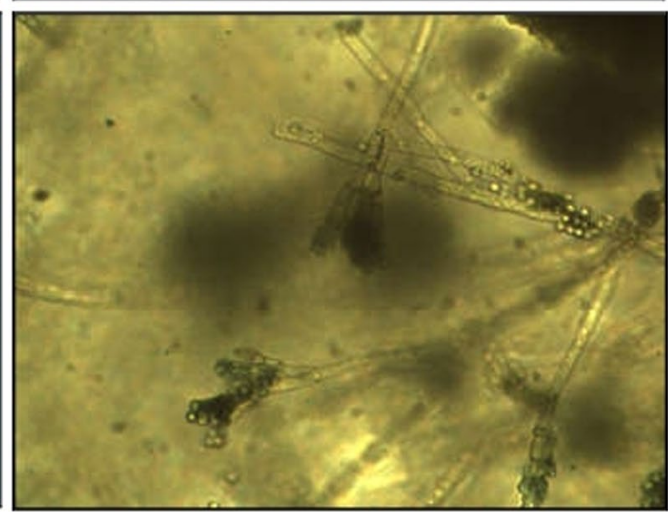

B

Fig. 1 Colonies and light micrographs of endophytic isolates from C. speciosa fruits. A Penicillium sp. I from peel. B Penicillium sp. II from pulp 
culmorum, while antifungal activity of Penicillium sp. II was found only against $A$. alternata (Fig. 2).

In the case of Penicillium sp. I action in dual culture assay, inhibition of $A$. alternata colony growth averaged $77.82 \%$ of control, and a decrease in colony size of $F . c u l-$ morum reached $76.24 \%$ compared to control. Antagonistic interaction of Penicillium sp. II with A. alternata caused the pathogenic colony growth inhibition above $84.71 \%$ of control (Table 1 ).

Study results of the endophytes interaction with pathogenic fungi assayed by agar disc method in Czapek's medium showed antagonistic activity of both Penicillium sp. I and Penicillium sp. II against all tested fungal pathogens (Fig. 3). The fungistatic potential of endophyte Penicillium sp. I was confirmed by the formation of inhibition zones with average diameter of $13.92 \mathrm{~mm}, 20.60 \mathrm{~mm}$ and $28.14 \mathrm{~mm}$ respectively in the colonies of $A$. alternata, F. culmorum and F. oxysporum. Antagonistic activity of Penicillium sp. II was found to be less noticeable producing the inhibition zones with a diameter of $12.90 \mathrm{~mm}$, $15.41 \mathrm{~mm}$, and $15.22 \mathrm{~mm}$, respectively in the colonies of A. alternata, F. culmorum, and F. oxysporum (Table 1).

\subsection{Antibacterial activity evaluation}

Results obtained showed bioactivity of all tested crude ethyl acetate extracts of both endophytes against Bacillus subtilis and Erwinia dissolvens in the disc diffusion assay (Fig. 4).

Inhibition zones produced by Penicillium sp. I cultural medium extracts were more noticeable as compared to effect of Penicillium sp. II extracts, while the opposite result was shown by the mycelium biomass extract (Table 2). Antibacterial activity both of Penicillium sp. I and Penicillium sp. II cultural medium extracts exceeded the activity of mycelium extracts. Cultural medium extracts of both endophytes showed higher activity against Gram-positive B. subtilis, while mycelium biomass extracts were more active against Gram-negative $E$. dissolvens. Ethyl acetate individual action did not affect bacteria growth.

\subsection{GC-MS analysis of the fungal secondary metabolites component composition}

The results of GC-MS analysis of Penicillium sp. I cultural medium ethyl acetate extracts showed the identity of 27 compounds belonging to different chemical classes. The most abundant compounds (Table 3) were represented by 3-Furanacetic acid, 4-hexyl-2,5-dihydro-2,5-dioxo- (49.95\%), Diisooctyl phthalate (14.29\%), 11-Hexadecyn-1-ol (13.19\%), and Propanedioic acid, dihydroxy (9.09\%). Among the 13 minor components of EtOAc extracts, which in total amounted to $2 \%$ of all only, the most notable were Cyclopentatrione, 3-butyl

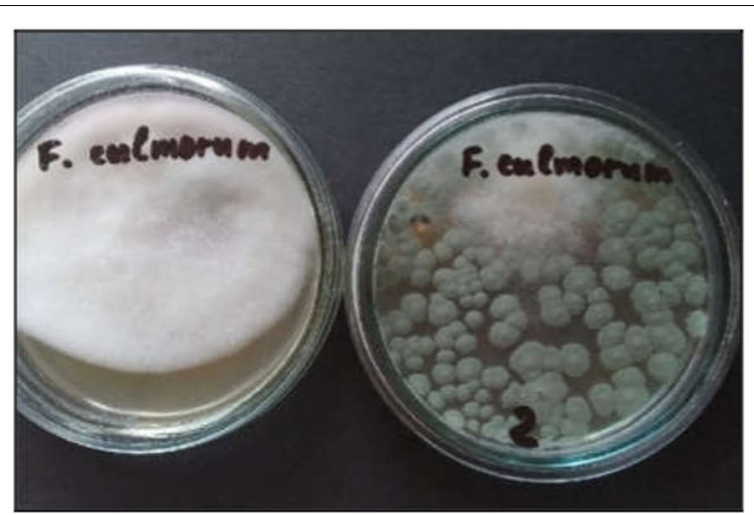

A

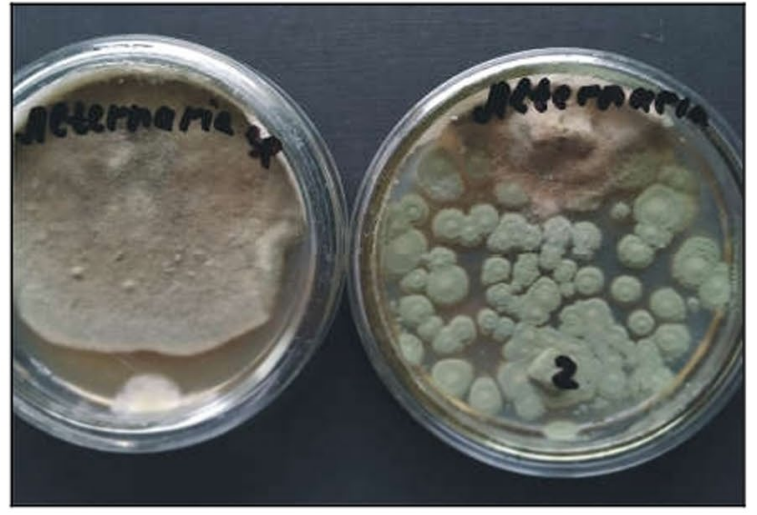

B

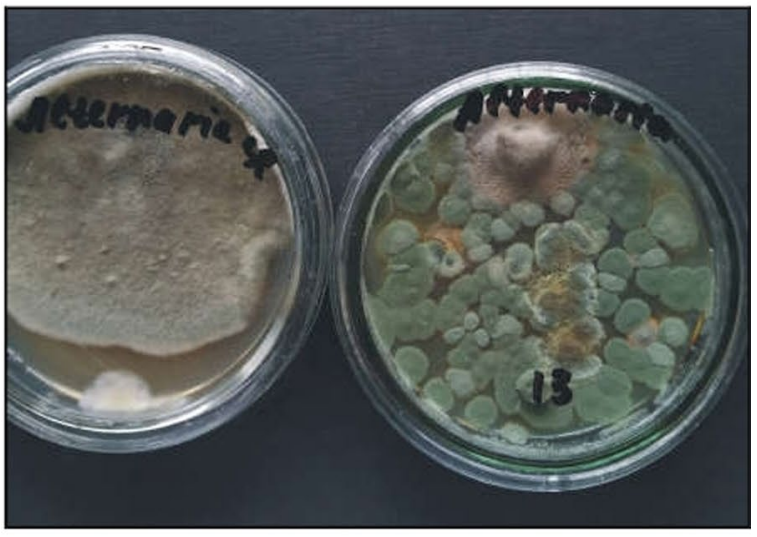

C

Fig. 2 Antagonistic activity of C. speciosa isolates as observed in dual culture assay on PDA medium. A Penicillium sp. I against F. culmorum. B Penicillium sp. I against A. alternata. C Penicillium sp. II against $A$. alternata

$(0.12 \%)$, di-Mevalonic acid lactone $(0.10 \%)$, Octadecanoic acid $(0.10 \%)$, Ribitol $(0.09 \%)$, Imidazole, 2-amino5-[(2-carboxy) vinyl (0.08\%), and 1H-Pyrazole, 3-Methyl (0.08\%).

The GC-MS analysis of Penicillium sp. II ethyl acetate extracts predominantly revealed the presence of 
Table 1 Antifungal activity of endophytes isolated from C. speciosa fruits

\begin{tabular}{|c|c|c|c|c|}
\hline \multirow[t]{2}{*}{ Test pathogens } & \multicolumn{2}{|c|}{ Percent of inhibition (PI \%) by dual culture assay ${ }^{1}$} & \multicolumn{2}{|c|}{$\begin{array}{l}\text { Inhibition zone diameter }(\mathrm{mm}) \text { by agar disc } \\
\text { method }^{1}\end{array}$} \\
\hline & Penicillium sp. I & Penicillium sp. II & Penicillium sp. I & Penicillium sp. II \\
\hline $\begin{array}{l}\text { Alternaria alternata } \\
\text { (KMB-F-16) }\end{array}$ & $77.82 \pm 2.91^{\mathrm{a}}$ & $84.71 \pm 1.23^{b}$ & $13.92 \pm 0.34^{\mathrm{a}}$ & $12.90 \pm 0.44^{b}$ \\
\hline $\begin{array}{l}\text { Fusarium culmorum } \\
\text { (IMB-F-50716) }\end{array}$ & $76.24 \pm 3.12$ & NA & $20.60 \pm 1.92^{\mathrm{a}}$ & $15.41 \pm 0.23^{b}$ \\
\hline $\begin{array}{l}\text { Fusarium oxysporum } \\
\text { (IMB-F-54201) }\end{array}$ & NT & NT & $28.14 \pm 0.31^{\mathrm{a}}$ & $15.22 \pm 0.31^{b}$ \\
\hline
\end{tabular}

${ }^{1}$ Data are expressed as the means of triplicate $\pm(S D)$. Values with different superscripts in each line are significantly different according to Tukey's test (P $\left.<0.05\right)$. NA no activity. NT not tested

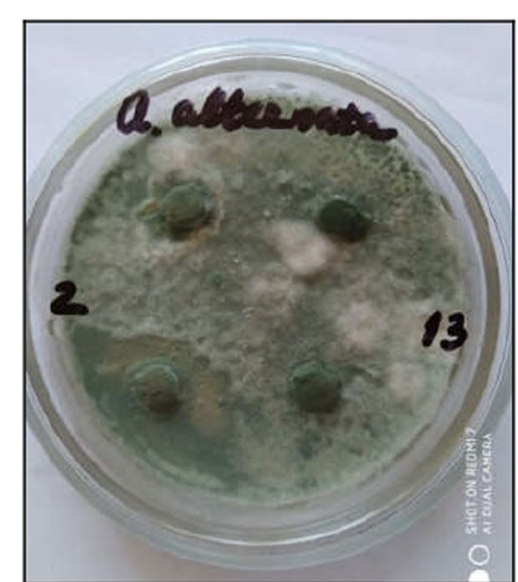

A

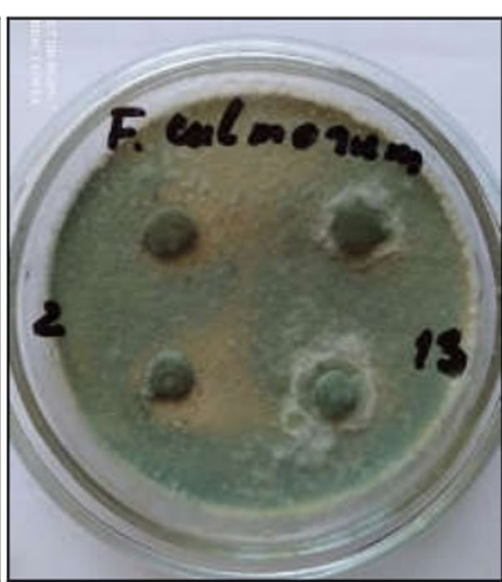

B

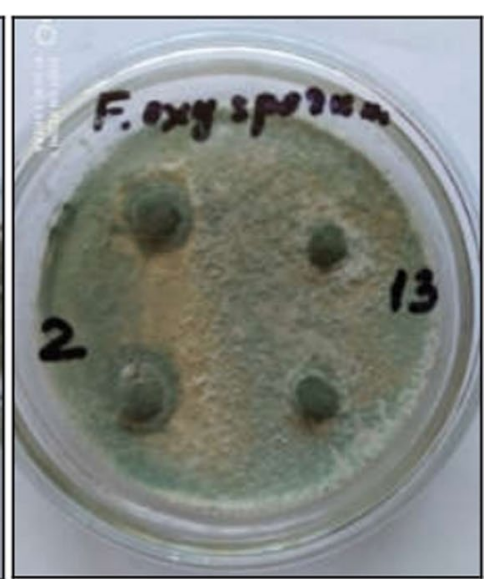

C

Fig. 3 Antagonistic activity of C. speciosa endophytic isolates assayed by agar disc method. A A. alternata. B F. culmorum. C F. oxysporum. 2-Penicillium sp. I, 13-Penicillium sp. II

17 chemical compounds belonging to different classes, mainly to acids, esters and alcohols (Table 4). The main constituents of this EtOAc extracts were Phthalic acid diisooctyl ester (82.42\%) and other phthalates, making up $87.72 \%$ of all identified compounds. Among other components, the most significant were Hexadecanoic acid (4.79\%), Eicosyl isopropyl ether (1.85\%), and 4-Butoxy2-butanone (1.65\%).

\section{Discussion}

Despite a long history of the genus Chaenomeles species cultivation and the known tolerance to climatic conditions and pathogens, endophytic microorganisms associated with these plants have been little studied. To test the hypothesis about the possible endophytes contribution to the $C$. speciosa resistance to biotic and abiotic stimuli, we investigated antimicrobial potential of the fungal isolates from the fruits peel and pulp, as well as the secondary metabolites composition of isolates. Studies of the plant fruits endophytic microflora are few at the moment. Known data are reports of endophytic fungus from the Sapindus saponaria fruits showed the ability to biotransform glycosides [24], and fungus from the Melia azedarach fruits which capable of synthesizing polyketide citrinin that inhibit Leishmania growth [25].

In our work, endophytic fungi were found both in the C. speciosa fruit peel and pulp and represented by three different genera. All of the fungal isolates attributed to the Penicillium genus were active against more than one test microorganism; however, potential of Penicillium sp. I from fruit peel and Penicillium sp. II from fruit pulp was more revealing. Both selected isolates inhibited growth of the phytopathogenic fungi A. alternata and F. oxysporum, while only Penicillium sp. I showed a noticeable antagonism against F. culmorum. In our study, $A$. alternata and F. culmorum strains were used as the test objects, since they parasitize on various fruit plants, including some Chaenomeles species [18]. At the same time, Wang et al. [6] reported A. alternata as the endophytic fungus isolated from Camellia sinensis branches. 


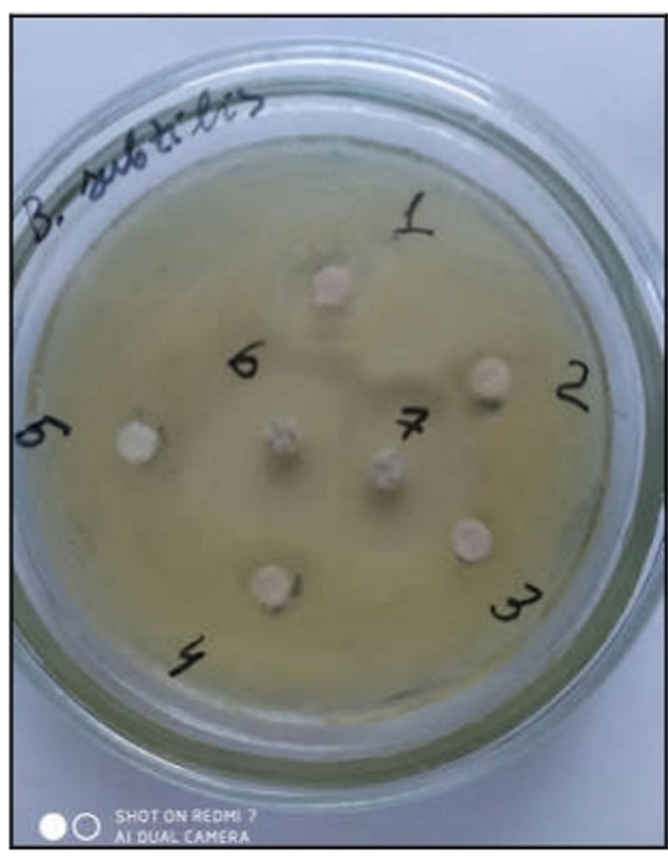

A

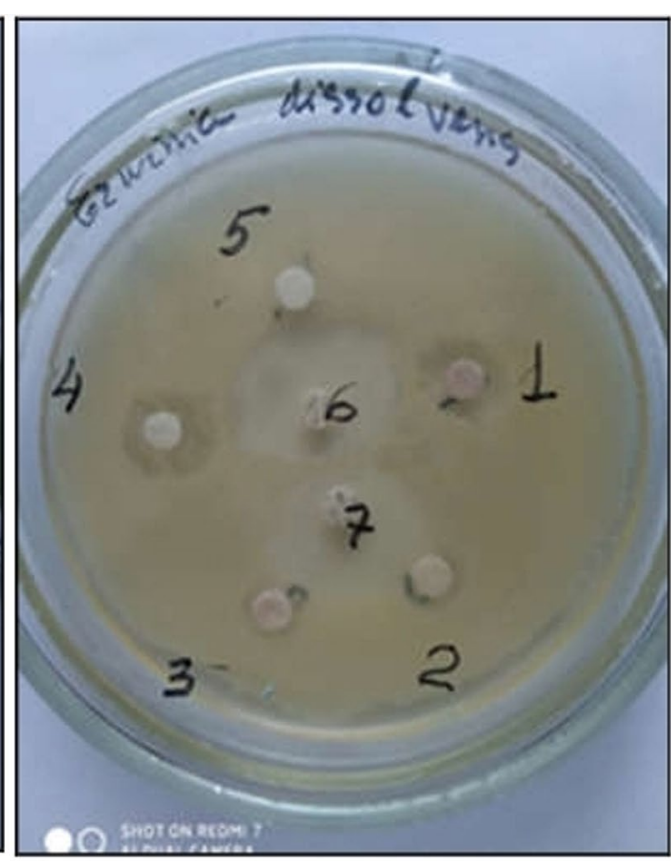

B

Fig. 4 Antibacterial activity of EtOAc extracts of C. speciosa fruit endophytic isolates. A Bacillus subtilis. B Erwinia dissolvens. 1—Penicillium sp. I cultural medium, 2-Penicillium sp. II cultural medium, 3-Penicillium sp. I mycelium, 4-Penicillium sp. II mycelium, 5-EtOAc, 6—ofloxacin, 7ceftriaxone

Table 2 Antibacterial activity of ethyl acetate extracts of C. speciosa fruit endophytic isolates ${ }^{1}$

\begin{tabular}{|c|c|c|c|c|}
\hline Endophyte name & Extractive substrate & $\begin{array}{l}\text { Extract content, } \\
\mu \mathrm{g} \text { per disc }\end{array}$ & Bacillus subtilis & Erwinia dissolvens \\
\hline \multirow[t]{2}{*}{ Penicillium sp. I } & Cultural medium & 20.0 & $19.0 \pm 3.61^{\mathrm{a}}$ & $14.67 \pm 3.06^{\mathrm{a}}$ \\
\hline & Mycelium biomass & 6.0 & $9.33 \pm 0.58^{b}$ & $9.52 \pm 0.50^{b}$ \\
\hline \multirow[t]{2}{*}{ Penicillium sp. II } & Cultural medium & 38.0 & $14.0 \pm 1.00^{\mathrm{ab}}$ & $11.33 \pm 1.15^{\mathrm{ab}}$ \\
\hline & Mycelium biomass & 6.0 & $12.33 \pm 1.53^{b}$ & $14.00 \pm 2.00^{\mathrm{ab}}$ \\
\hline Ofloxacin & & & $25.33 \pm 2.08^{c}$ & $23.33 \pm 1.15^{c}$ \\
\hline Ceftriaxone & & & $25.33 \pm 0.58^{c}$ & $24.33 \pm 2.08^{c}$ \\
\hline Ethyl acetate & & & NA & NA \\
\hline
\end{tabular}

${ }^{1}$ Data on the inhibition zone diameter $(\mathrm{mm})$ are expressed as the means of triplicate $\pm(\mathrm{SD})$. Values with different superscripts in each column are significantly different according to Tukey's test $(P<0.05)$. NA no activity

Like this, F. culmorum as the endophyte can confer salt tolerance to the coastal plant Leymus mollis [26]. There is no contradiction here, since fungal species are characterized by the ability to enter into different forms of symbiosis, expressing either a mutualistic or pathogenic lifestyle in different host plants [27].

Antibacterial activity against Gram-positive B. subtilis and Gram-negative E. dissolvens was found in the ethyl acetate extracts of culture medium and mycelium of both studied isolates; however, antibacterial activity of Penicillium sp. I was higher, as was its antifungal potential. In general, the study results are consistent with the known data on a wide spectrum of antimicrobial activity of the endophytic fungi secondary metabolites, shown by Aspergillus fumigatus [7], Botryosphaeria dothidea [8], and Aspergillus clavatonanicus [21].

According to GC-MS assay, both Penicillium sp. I and Penicillium sp. II produced the pool of different chemical compounds, including fatty acids, esters and ethers, alcohols, and aldehydes. The study results confirm the known ability of the genus Penicillium for the various secondary metabolites biosynthesis [28]. The 
Table 3 Main metabolites content of isolate Penicillium sp. I as identified by GC-MS analysis

\begin{tabular}{lclrll}
\hline $\begin{array}{l}\text { Peak } \\
\text { no }\end{array}$ & $\begin{array}{l}\text { RT1, } \\
\text { min }\end{array}$ & Compound name & Area, \% & Molecular formula & Class \\
\hline 1 & 1.46 & Propanedioic acid, dihydroxy & 9.09 & $\mathrm{C}_{3} \mathrm{H}_{4} \mathrm{O}_{6}$ & \\
2 & 2.23 & 2-Butenoic acid, 3-Methyl & 0.30 & $\mathrm{C}_{5} \mathrm{H}_{8} \mathrm{O}_{2}$ & Acid \\
3 & 4.24 & Pentanedioic acid, 3-(1,2-diphenyl-propyliden), monomethyl ester & 1.61 & $\mathrm{C}_{21} \mathrm{H}_{22} \mathrm{O}_{4}$ & Acid \\
4 & 4.51 & Propanedioic acid, phenyl & 0.57 & $\mathrm{C}_{9} \mathrm{H}_{8} \mathrm{O}_{4}$ & Ester \\
5 & 5.23 & Benzenamine, 3-Methoxy-4-[3(1-piperidinyl)propoxy]- & 2.45 & $\mathrm{C}_{15} \mathrm{H}_{24} \mathrm{~N}_{2} \mathrm{O}_{2}$ & Acid \\
6 & 5.68 & Benzeneethanol, 4-hydroxy & 1.31 & $\mathrm{C}_{8} \mathrm{H}_{10} \mathrm{O}_{2}$ & Aromatic amine \\
7 & 6.03 & 3-Furanacetic acid, 4-hexyl-2,5-dihydro-2,5-dioxo- & 49.95 & $\mathrm{C}_{12} \mathrm{H}_{16} \mathrm{O}_{5}$ & Alcohol \\
8 & 6.22 & 11-Hexadecyn-1-ol & 13.19 & $\mathrm{C}_{16} \mathrm{H}_{30} \mathrm{O}$ & Acid \\
9 & 6.32 & 7-Hexadecenal & 0.42 & $\mathrm{C}_{16} \mathrm{H}_{30} \mathrm{O}$ & Alcohol \\
10 & 8.26 & Hexadecanoic acid & 0.95 & $\mathrm{C}_{16} \mathrm{H}_{32} \mathrm{O}_{2}$ & Aldehyde \\
11 & 8.35 & Phthalic acid, butyl tridecyl ester & 0.64 & $\mathrm{C}_{25} \mathrm{H}_{40} \mathrm{O}_{4}$ & Fatty acid \\
12 & 8.65 & Henicosanal & 2.32 & $\mathrm{C}_{21} \mathrm{H}_{42} \mathrm{O}$ & Ester \\
13 & 9.04 & Octadec-9-enoic acid & 0.51 & $\mathrm{C}_{18} \mathrm{H}_{34} \mathrm{O}_{2}$ & Aldehyde \\
14 & 10.88 & Phthalic acid, diisooctyl ester & 14.29 & $\mathrm{C}_{24} \mathrm{H}_{38} \mathrm{O}_{4}$ & Fatty acid
\end{tabular}

Data on compounds content are expressed as peak area (\% of total amounts)

$R T$ Retention time

Table 4 Main metabolites content of isolate Penicillium sp. II as identified by GC-MS analysis

\begin{tabular}{|c|c|c|c|c|c|}
\hline $\begin{array}{l}\text { Peak } \\
\text { no }\end{array}$ & $\begin{array}{l}\mathrm{RT}^{1} \\
\min ^{2}\end{array}$ & Compound name & Area, $\%$ & Molecular formula & Class \\
\hline 1 & 1.84 & 4-Butoxy-2-butanone & 1.65 & $\mathrm{C}_{8} \mathrm{H}_{16} \mathrm{O}_{2}$ & Ketone \\
\hline 2 & 4.57 & 9-Oxononanoic acid & 0.30 & $\mathrm{C}_{9} \mathrm{H}_{16} \mathrm{O}_{3}$ & Acid \\
\hline 3 & 5.99 & 3-Furanacetic acid, 4-hexyl-2,5-dihydro-2,5-dioxo- & 0.38 & $\mathrm{C}_{12} \mathrm{H}_{16} \mathrm{O}_{5}$ & Acid \\
\hline 4 & 6.07 & 9-Methyl-10-pentadecen-1-ol & 0.31 & $\mathrm{C}_{16} \mathrm{H}_{32} \mathrm{O}$ & Alcohol \\
\hline 5 & 6.20 & 8,10-Hexadecadien-1-ol & 0.34 & $\mathrm{C}_{16} \mathrm{H}_{30} \mathrm{O}$ & Alcohol \\
\hline 6 & 7.00 & 1-Hexadecanol & 0.38 & $\mathrm{C}_{16} \mathrm{H}_{34} \mathrm{O}$ & Alcohol \\
\hline 7 & 7.62 & Tetradecanoic acid, 1-methylethyl ester & 0.63 & $\mathrm{C}_{17} \mathrm{H}_{34} \mathrm{O}_{2}$ & Ester \\
\hline 8 & 7.92 & Bis(tridecyl) phthalate & 0.40 & $\mathrm{C}_{34} \mathrm{H}_{58} \mathrm{O}_{4}$ & Ester \\
\hline 9 & 8.04 & Octanoic acid, oct-3-en-2-yl ester & 0.36 & $\mathrm{C}_{16} \mathrm{H}_{30} \mathrm{O}_{2}$ & Ester \\
\hline 10 & 8.26 & Hexadecanoic acid & 4.79 & $\mathrm{C}_{16} \mathrm{H}_{32} \mathrm{O}_{2}$ & Fatty acid \\
\hline 11 & 8.35 & Phthalic acid, butyl tridecyl ester & 1.78 & $\mathrm{C}_{25} \mathrm{H}_{40} \mathrm{O}_{4}$ & Ester \\
\hline 12 & 8.80 & Nonadecanol-1 & 0.54 & $\mathrm{C}_{19} \mathrm{H}_{40} \mathrm{O}$ & Alcohol \\
\hline 13 & 9.05 & Octadec-9-enoic acid & 0.75 & $\mathrm{C}_{18} \mathrm{H}_{43} \mathrm{O}_{2}$ & Fatty acid \\
\hline 14 & 9.59 & Phthalic acid, isobutyl octadecyl ester & 1.55 & $\mathrm{C}_{30} \mathrm{H}_{50} \mathrm{O}_{4}$ & Ester \\
\hline 15 & 10.95 & Phthalic acid, diisooctyl ester & 82.42 & $\mathrm{C}_{24} \mathrm{H}_{38} \mathrm{O}_{4}$ & Ester \\
\hline 16 & 12.02 & Phthalic acid, di(2-ethylhexyl) ester & 1.57 & $\mathrm{C}_{24} \mathrm{H}_{38} \mathrm{O}_{4}$ & Ester \\
\hline 17 & 12.96 & Eicosyl isopropyl ether & 1.85 & $\mathrm{C}_{23} \mathrm{H}_{48} \mathrm{O}$ & Ether \\
\hline
\end{tabular}

Data on compounds content are expressed as peak area (\% of total amounts)

1 RT Retention time

Furanacetic acid derivative (3-Furanacetic acid, 4-hexyl2,5-dihydro-2,5-dioxo-) which is a significant component of both Penicillium sp. I and Penicillium sp. II ethyl acetate extracts, may presumably exhibit biological activity similar to other furancarboxylic acid derivatives having the antibacterial and antifungal potential [29]. Alcohol
11-Hexadecyn-1-ol, produced by Penicillium sp. I, was characterized [30] as plant esseinial oil component having high antioxidant potential. Phenylmalonic acid contained in the Penicillium sp. I ethyl acetate extract, was reported [31] as bioactive compound. Antifungal activity was shown by acetic acid, 2-methylpropyl ester [32] 
and benzene ethanol [33], which were identified in our work in the cultural medium of isolate Penicillium sp. I. Imidazole, 2-amino-5-[(2-carboxy) vinyl] revealed in the Pencillium sp. I ethyl acetate extract, was reported [34] as metabolite of pome fruits pathogen Penicillium expansum showed a wide range of antibacterial activity. Both fruit isolates Penicillium sp. I and Penicillium sp. II exhibited the ability to synthesize Cis-9-octadecenoic acid, which is known due to versatile health benefits including cancer preventive, hypocholesterolemic, antiinflammatory, and choleretic action [35].

The high content of phthalic acid esters produced by both Pencillium sp. I and Pencillium sp. II was not expected in our work, but at the same time it is not a unique finding. Bhimba et al. [23] designated Dibutyl phthalate and Mono (2-ethylhexyl) phthalate produced by the marine fungi Phoma herbarum among the major components of fungal filtrates, which exhibited the wide spectrum of antibacterial activity. Phthalic acid, butyl undecyl ester was identified in the methanolic extract of Penicillium expansum [34]. Lotfy et al. [22] reported Di(2-ethylhexyl) phthalate as the most abundant bioactive metabolite produced by fungus Aspergillus awamori, exhibited activity against Candida albicans and the Gram positive bacteria Sarcina lutea, and also cytotoxic activity against some carcinoma cell lines. A specific feature of the Pencillium sp. I and Pencillium sp. II isolated from the $C$. speciosa fruit consists of the variety of phthalic acid esters produced by these fungi. In total, five different phthalates have been identified in the fungal ethyl acetate extracts. Among them, Diisooctyl phthalate and Butyl tridecyl phthalate were synthesized by both isolates, with the first compound dominance in the metabolites. Only Pencillium sp. II produced Bis(tridecyl) phthalate, Isobutyl octadecyl phthalate, and Di(2-ethylhexyl) phthalate. These data allow us to consider the action of metabolites with known biological activity as a possible basis for the antimicrobial ability of Penicillium sp. I and Penicillium sp. II. However, further research is needed in order to carry out large-scale cultivation of the fungal isolates, to obtain the synthesized individual compounds and to identify their bioactivity.

\section{Conclusions}

In our study, nine fungal endophytes were isolated from C. speciosa fruits. All the fungal isolates attributed to Penicillium genus were moderately active against more than one tested pathogens; however, the antimicrobial potential of the fruit peel isolate Pencillium sp. I was more pronounced than of fruit pulp isolate Pencillium sp. II. The secondary metabolites of both cultured isolates contain several compounds with known antimicrobial activity, which indicates the further study advisability of the fruit-associated endophytes biosynthetic potential. The findings also indicate that the endophytic community of fruit plants resistant to pathogens and adverse environment can be a rich source of new bioactive compounds.

\section{Abbreviations}

EtOAc: Ethyl acetate; CFU: Colony Forming Units; GC-MS: Gas Chromatography-Mass Spectrometry; MPA: Meat Peptone Agar; PDA: Potato Dextrose Agar; PI: Percent Inhibition; RT: Retention Time.

\section{Acknowledgments}

Not applicable.

\section{Authors' contributions}

Concept developing: YVL and NOK. Experiments and methodology: OAD, AOA, TVS, OOD, and NOK. Data and statistical analysis: OOD, AOA, and TVS. Writing draft manuscript: NOK and OAD. Writing - review and editing manuscript:YVL, NOK, TVS, and OOD. Supervision: YVL, NOK and OOD. All authors have read and approved the final manuscript.

\section{Funding}

This study was performed in scope of the scientific project "Biologically active substances of less-common fruit plants as the effective means of improving products quality and raw materials value for the functional nutrition (registration number 0121U109772) financed by Ministry of Education and Science of Ukraine.

\section{Ethical approval and consent to participate}

Not applicable.

\section{Consent for publication}

Not applicable.

\section{Availability of data and materials}

The datasets used and/or analysed during the current study are available from the corresponding author on reasonable request.

\section{Competing interests}

The authors declare that they have no competing interests.

\section{Author details}

${ }^{1}$ Plant Physiology Department, Faculty of Biology and Medicine, Oles Honchar Dnipro National University, Gagarin Av., 72, Dnipro 49010, Ukraine. ${ }^{2}$ Biology Research Institute, Oles Honchar Dnipro National University, Gagarin Avenue, 72, Dnipro 49010, Ukraine. ${ }^{3}$ Microbiology, Virology and Biotechnology Department, Faculty of Biology and Medicine, Oles Honchar Dnipro National University, Gagarin Av., 72, Dnipro 49010, Ukraine. ${ }^{4}$ Organic Chemistry Department, Faculty of Chemistry, Oles Honchar Dnipro National University, Gagarin Av., 72, Dnipro 49010, Ukraine.

Received: 25 August 2021 Accepted: 8 November 2021

Published online: 27 November 2021

References

1. Arnold AE, Mejía LC, Kyllo D, Rojas El, Maynard Z, Robbins N, Herre EA (2003) Fungal endophytes limit pathogen damage in a tropical tree. Proc Natl Acad Sci USA 100:15649-15654. https://doi.org/10.1073/pnas.25334 83100

2. Blumenstein $K$, Albrectsen BR, Martín JA, Hultberg M, Sieber TN, Helander M, Witzell J (2015) Nutritional niche overlap potentiates the use of endophytes in biocontrol of a tree disease. Biocontrol 60:655-667. https://doi. org/10.1007/s10526-015-9668-1

3. Gunatilaka AAL (2006) Natural products from plant-associated microorganisms: distribution, structural diversity, bioactivity, and implications of their occurrence. J Nat Prod 69(3):509-526. https://doi.org/10.1021/ np058128n 
4. Nicoletti R, Fiorentino A (2015) Plant bioactive metabolites and drugs produced by endophytic fungi of Spermatophyta. Agriculture 5:918-970. https://doi.org/10.3390/agriculture5040918

5. Zheng YK, Qiao XG, Miao CP, Liu K, Chen Y-W, Li-H Xu, Li-X Z (2016) Diversity, distribution and biotechnological potential of endophytic fungi. Ann Microbiol 66:529-542. https://doi.org/10.1007/s13213-015-1153-7

6. Wang Y, Yang M-H, Wang X-B, Li T-X, Kong LY (2014) Bioactive metabolites from the endophytic fungus Alternaria alternata. Fitoterapia 99(12):153158. https://doi.org/10.1016/j.fitote.2014.09.015

7. Li X-J, Zhang Q, Zhang A-L, Gao JM (2012) Metabolites from Aspergillus fumigatus, an endophytic fungus associated with Melia azedarach, and their antifungal, antifeedant, and toxic activities. J Agric Food Chem 60(13):3424-3431. https://doi.org/10.1021/jf300146n

8. Xiao J, Zhang O, Gao Y-O, Tang J-J, Zhang A-L, Gao J-M (2014) Secondary metabolites from the endophytic Botryosphaeria dothidea of Melia azedarach and their antifungal, antibacterial, antioxidant, and cytotoxic activities. J Agric Food Chem 62(16):3584-3590. https://doi.org/10.1021/ jf500054f

9. Kaur N, Arora DS, Kalia N, Kaur M (2020) Bioactive potential of endophytic fungus Chaetomium globosum and GC-MS analysis of its responsible components. Sci Rep 10(1):18792. https://doi.org/10.1038/ s41598-020-75722-1

10. Thakur JP, Haider R, Singh DK, Kumar BS, Vasudev PG, Luqman S, Kalra A, Saikia D, Negi AS (2015) Bioactive isochromenone isolated from Aspergillus fumigatus, endophytic fungus from Bacopa monnieri. Microbiol Res 6:5800. https://doi.org/10.4081/mr.2015.5800

11. Nurunnabi TR, Sarwar S, Sabrin F, Alam F, Nahar L, Sohrab H, Sarker SD, Rahman SMM, Billah M (2020) Molecular identification and antimicrobial activity of endophytic fungi isolated from Heritiera fomes (Buch.-Ham), a mangrove plant of the Sundarbans. BJBAS 9:61. https://doi.org/10.1186/ s43088-020-00081-9

12. Yang L, Ahmed S, Stepp JR, Zhao Y, Zeng MJ, Pei S, Xue D, Xu G (2015) Cultural uses, ecosystem services, and nutrient profile of Flowering Quince (Chaenomeles speciosa) in the Highlands of Western Yunnan. China Econ Bot 69(3):273-283. https://doi.org/10.1007/s12231-015-9318-7

13. Du H, Wu J, Li H, Zhong PX, Xu YJ, Li CH, Ji KX, Wang LS (2013) Polyphenols and triterpenes from Chaenomeles fruits: chemical analysis and antioxidant activities assessment. Food Chem 141(4):4260-4268. https:// doi.org/10.1016/j.foodchem.2013.06.109

14. Miao J, Zhao C, Li X, Chen X, Mao X, Huang H, Wang T, Gao W (2016) Chemical composition and bioactivities of two common Chaenomeles fruits in China: Chaenomeles speciosa and Chaenomeles sinensis. J Food Sci 81(8):H2049-2058. https://doi.org/10.1111/1750-3841.13377

15. Lykholat YV, Khromykh NO, Lykholat TY, Didur OO, Lykholat OA, Legostaeva TV, Kabar AM, Sklyar TV, Savosko VM, Kovalenko IM, Davydov VR, Bielyk YV, Volyanik KO, Onopa AV, Dudkina KA, Grygoryuk IP (2019) Industrial haracteristics and consumer properties of Chaenomeles Lindl. Fruits. Ukr J Ecol 9(3):132-137

16. Khromykh N, Lykholat Y, Shupranova L, Kabar A, Didur O, Lykholat T, Kulbachko Y (2018) Interspecific differences of antioxidant ability of introduced Chaenomeles species with respect to adaptation to the steppe zone conditions. Biosyst Divers 26(2):132-138. https://doi.org/10.15421/ 011821

17. Khromykh N, Lykholat Y, Anishchenko A, Didur O, Gaponov A, Kabar M, Lykholat $Y$ (2020) Cuticular wax composition of mature leaves of species and hybrids of the genus Prunus differing in resistance to clasterosporium disease. Biosyst Divers 28(4):370-375. https://doi.org/10.15421/012047

18. Fedulova Y, Kuklina A, Sorokopudov V, Sorokopudova O, Shlapakova S, Lukashov Y, Fayzrakhmanov D, Ziganshin B, Nezhmetdinova F, Shaydullin $R$ (2020) Screening of phytopathogens and phytopathoges on Chenomeles (CHAENOMELES LINDL.) cultivars. BIO Web Conf 17(1-2):00245. https://doi.org/10.1051/bioconf/20201700245

19. Ni H, Kong W-L, Zhang Q-Q, Wu X-Q (2021) First Report of leaf spot disease caused by Colletotrichum gloeosporioides on Chaenomeles sinensis in China. Plant Dis. https://doi.org/10.1094/pdis-11-20-2488-pdn

20. Zhu X, Yang A, Zheng Y, Wei X, Wang J (2009) Primary research on arbuscular mycorrhizal fungi in rhizosphere of Chaenomeles speciosa in Xuancheng. Zhongguo Zhong Yao Za Zhi 34(7):820-824

21. Mishra VK, Passari AK, Chandra P, Leo VV, Kumar B, Uthandi S, Thankappan S, Gupta VK, Singh BP (2017) Determination and production of antimicrobial compounds by Aspergillus clavatonanicus strain MJ31, an endophytic fungus from Mirabilis jalapa L. using UPLC-ESI-MS/MS and TD-GC-MS analysis. PLoS One 12(10):e0186234. https://doi.org/10.1371/ journal.pone.0186234

22. Lotfy MM, Hassan HM, Hetta MH, El-Gendy AO, Mohammed R (2018) Di(2ethylhexyl) Phthalate, a major bioactive metabolite with antimicrobial and cytotoxic activity isolated from River Nile derived fungus Aspergillus awamori. BJBAS 7(3):263-269. https://doi.org/10.1016/j.bjbas.2018.02.002

23. Bhimba BV, Pushpam AC, Arumugam P, Prakash S (2012) Phthalate derivatives from the marine fungi Phoma herbarum VB7. IJBPR 3(4):507-512

24. Amaral LS, Murgu M, Rodrigues-Fo E, de Souza AQ, de Moura Sarquis MI (2008) A saponin tolerant and glycoside producer xylariaceous fungus isolated from fruits of Sapindus saponaria. World J Microbiol Biotechnol 24(8):1341-1348. https://doi.org/10.1007/s11274-007-9607-0

25. Marinho AMR, Rodrigues-Filho E, Moitinho MLR, Santos LS (2005) Biologically active polyketides produced by Penicillium janthinellum isolated as an endophytic fungus from fruits of Melia azedarach. J Braz Chem Soc 16:280-283. https://doi.org/10.1590/S0103-50532005000200023

26. Rodriguez RJ, Henson J, Van Volkenburgh E, Hoy M, Wright L, Beckwith F, Kim Y, Redman RS (2008) Stress tolerance in plants via habitat-adapted symbiosis. ISME J 2:404-416. https://doi.org/10.1038/ismej.2007.106

27. Strobel G, Daisy B, Castillo U, Harper I (2004) Natural products from endophytic microorganisms. J Nat Prod 67(2):257-268. https://doi.org/10. 1021/np030397v

28. Toghueo RMK, Boyom FF (2020) Endophytic Penicillium species and their agricultural, biotechnological, and pharmaceutical applications. 3 Biotech 10:107. https://doi.org/10.1007/s13205-020-2081-1

29. Chang J-L, Xu H-Z, Zhou J, Zhou M, Zhang X, Guo Y, Ruan H-L (2020) Antimicrobial Furancarboxylic Acids from a Penicillium sp. J Nat Prod 83(12):3606-3613. https://doi.org/10.1021/acs.jnatprod.0c00758

30. Ahmad S, Ullah F, Sadiq A, Ayaz M, Imran M, Ali I, Zeb A, Ullah F, Shah MR (2016) Chemical composition, antioxidant and anticholinesterase potentials of essential oil of Rumex hastatus D. Don collected from the North West of Pakistan. BMC Complement Altern Med 16:29. https://doi.org/10. 1186/s12906-016-0998-z

31. ur Rahman L, Ikenaga T, Kitamura Y (2004) Penicillin derivatives induce chemical structure-dependent root development, and application for plant transformation. Plant Cell Rep 22:668-677. https://doi.org/10.1007/ s00299-003-0731-5

32. Banerjee D, Pandey A, Jana M, Strobel GA (2014) Muscodor albus MOW12 an endophyte of Piper nigrum L. (Piperacae) collected from North east India produces volatile antimicrobials. Indian J Microbiol 54:27-32. https://doi.org/10.1007/s12088-013-0400-5

33. Singh SK, Strobel GA, Knighton B, Geary B, Sears J, Ezra D (2011) An endophytic Phomopsis sp. possessing bioactivity and fuel potential with its volatile organic compounds. Microb Ecol 61:729-739. https://doi.org/ 10.1007/s00248-011-9818-7

34. Hamza LF, Kamal SA, Hameed IH (2015) Determination of metabolites products by Penicillium expansum and evaluating antimicrobial activity. J Pharmacogn Phytotherapy 7(9):194-220. https://doi.org/10.5897/JPP20 15.0360

35. Diab TA, Donia T, Saad-Allah KM (2021) Characterization, antioxidant, and cytotoxic effects of some Egyptian wild plant extracts. BJBAS 10:13. https://doi.org/10.1186/s43088-021-00103-0

\section{Publisher's Note}

Springer Nature remains neutral with regard to jurisdictional claims in published maps and institutional affiliations. 